\title{
The surgical treatment of cerebrospinal fistula: Qualitative and quantitative analysis of indications and results
}

\author{
Alessandra Iavarone MD $^{1} \quad$ | Paolo Luparello MD MD $^{1}$ । Maria Silvia Lazio MD I $^{1}$ \\ Lara Valentina Comini MD ${ }^{1}$ (1) I Federica Martelli MD $^{1}$ | Oliviero De Luca MD $^{2}$ । \\ Giovanni Paolo Santoro MD $^{2}$ ～Roberto Santoro MD $^{2}$ | Giammarco Alderotti PhD ${ }^{3}$ | \\ Giuditta Mannelli MD² (D)
}

${ }^{1}$ Unit of Otorhinolaryngology Head and Neck Surgery, Department of Surgery and Translational Medicine, University of

Florence, Florence, Italy

${ }^{2}$ Head and Neck and Robotic Surgery, Department of Experimental and Clinical Medicine, University of Florence, Florence, Italy

${ }^{3}$ Department of Statistics Science, University "La Sapienza" of Rome, Rome, Italy

\section{Correspondence}

Giuditta Mannelli, Head and Neck and

Robotic Surgery, Department of

Experimental and Clinical Medicine,

University of Florence, Florence 50141,

Italy.

Email: mannelli.giuditta@gmail.com

\begin{abstract}
Cerebrospinal fistula might occur in different ways. CSF closure techniques have undergone significant evolution that has led to the consolidation of the transnasal endoscopic approach. Despite the existence of multiple publications, meaningful information is still lacking in clinical practice and the literature about the ideal method, material, and timing for repair of CSF. The purpose of this review was to summarize the success rate of endoscopic CSF leak repair as well as whether specific techniques or materials influence the primary success rate through a review of the latest advancements in endoscopic CSF management published in the past 10 years. The principles of multilayer reconstructions and the routine use of vascularized flaps in expanded endonasal surgery have reduced postoperative CSF leaks' failure rates between 5\% and 10\% (4\% in this meta-analysis). Effective endoscopic anterior skull base (ASB) closure may be achieved by multiple reconstructive techniques, which should be tailored case by case according to the patient and defect conditions.
\end{abstract}

\section{K E Y W O R D S}

cerebrospinal fistula, endoscopic treatment, meta-analysis, systematic review, transnasal endoscopic surgery

\section{1 | INTRODUCTION}

The anterior skull base is a key barrier between the intracranial-intradural compartment and the sinonasal tract. Independent from their idiopathic, traumatic, postoperative, or tumoral nature, defects on the anterior skull base have to be closed meticulously. Historically, the closure of these defects was approached intracranially, using classic open skull base surgical procedures. Although the open intracranial approach provides a large surgical field and allows for direct visualization, it is associated with high morbidity, including intracerebral hemorrhage, cerebral edema, frontal lobe deficits, lengthened hospital stay, anosmia, and high recurrence rates. Over the past 50 years, cerebrospinal fistula closure techniques have undergone significant evolution. Minimally invasive approaches, characterized with improved success rates and decreased morbidity, have gained increasing interest over the traditional open craniotomy repair methods. ${ }^{1}$ After the craniotomy approach, the recurrence rate of CSF leaks has been reported to be as high as $27 \%$ after the first attempt, and $10 \%$ of patients have been reported to have persistent leaks despite multiple attempts. ${ }^{1}$ Dohlman described in 1948 a second extracranial approach for the repair of CSF rhinorrhea through a naso-orbital incision, ${ }^{2}$ and this external ethmoidectomy approach was also recommended by Chandler, who did not experience any 
intracranial complications requiring additional management during this surgical procedure. ${ }^{3}$ Later, the transnasal closure of sphenoid CSF leaks was first reported by Hirsch in 1952, ${ }^{4}$ and Vrabec and Hallberg described a cribriform plate leak repair using an intranasal approach by a simultaneous submucosal resection of the nasal septum for adequate. ${ }^{5}$ From their experience, Lehrer and Deutsch suggested the use of an operating microscope. ${ }^{6}$

Advancements in endoscopic technology and the development of minimally invasive surgical techniques have led to the progressive introduction of transnasal endoscopic CSF leaks' surgical management. The endoscopic approach was first mentioned by Wigand in $1981{ }^{7}$ and Mattox and Kennedy published a small case series in $1990 .{ }^{8}$ Subsequently, the transnasal endoscopic approach repair has become the standard of care for the operative management of most of the CSF leaks. ${ }^{9}$

\section{2 | CSF ETIOLOGY}

Cerebrospinal fluid (CSF) rhinorrhea denotes a skull base fistula connecting the subarachnoid space to the nasal cavity. Defects commonly occur in the ethmoid roof, the cribriform plate, and the sphenoid, while the frontal sinus and the posterior table are less involved. Lopatin and Kapitanov ${ }^{10}$ simply identified two categories: primary (spontaneous) and secondary CSF leaks, whereas Gendeh et $\mathrm{al}^{11}$ suggested to identify other three etiologic categories: congenital, acquired, and spontaneous. All the existing and recognized etiological categories have been reported in Table 1 .

Hassan et al $^{12}$ described accidental trauma as the most frequent cause of CSF (44\%), followed by surgical trauma (29\%) and tumors (22\%). Most commonly, the leak is found

T A B L E 1 Causes of cerebrospinal fluid rhinorrhea

\begin{tabular}{|ll}
\hline Idiopathic & Unknown causes \\
\hline Trauma_surgical & - "Open" surgery for inflammatory sinus \\
& disease \\
& - Endoscopic sinus surgery \\
& - Transcranial approaches \\
& - Transtemporal approaches \\
Trauma— & - Closed head injuries \\
nonsurgical & - Open or penetrating injuries \\
& - Posttraumatic hydrocephalus \\
Inflammatory & - Erosive lesions: mucoceles, polypoid \\
& - disease, cystic fibrosis, fungal sinusitis \\
Congenital & - Postinfectious hydrocephalus \\
& - Meningocele or meningoencephalocele \\
& - Congenital skull base defects \\
\hline Neoplasm & - Neoplasm invading the skull base \\
\hline
\end{tabular}

at the cribriform plate (35\%) and less frequently at the sphenoid sinus (26\%), anterior ethmoid (18\%), frontal sinus (10\%), posterior ethmoid (9\%), and inferior clivus (2\%). ${ }^{13}$ Locatelli et $\mathrm{al}^{14}$ reported the cribriform plate (23.1\%) and ethmoid skull base $(20.5 \%)$ as the most common sites of post-traumatic CSF, with an incidence of multiple sites of fractures in $35.9 \%$ of the patients. Iatrogenic injury most commonly occurs at the ethmoid skull base (35.1\%), the cribriform (27\%), and the sphenoid sinus (18.9\%). ${ }^{15}$ The most important factors leading to a higher risk of iatrogenic CSF leak are failure to recognize anatomical landmark, previous surgery, and others. Most authors agree, however, that previous endoscopic surgery (revision) constitutes the most common clinical scenario associated with this event. ${ }^{12}$ Congenital skull base defects are generally rare, and $63 \%$ of them occur in the foramen caecum. ${ }^{15}$ Spontaneous CSF (sCSF) rhinorrhea remains a diagnostic and surgical challenge. The frequency of spontaneous leaks has been reported to range between $15 \%$ and $23 \% .{ }^{13}$ The cribriform plate is the most common site of origin, although Gendeh et $\mathrm{al}^{11}$ found that $40 \%-56 \%$ of sCSF leaks occur in the sphenoid sinus and seems to be more common in females aged 40-59 years. Recent research studies ${ }^{16,17}$ have focused on the role of the intracranial pressure (ICP) in both the origin of SCSF leaks and in the increased failure rate associated with their surgical repair. In fact, high ICP is associated with $63 \%-88 \%$ of sCSF leaks; in addition, they are associated with a $50 \%-100 \%$ incidence of encephalocele and a $25 \%-87 \%$ incidence of recurrence. ${ }^{18}$ Their etiology is not completely understood, but there is a clear association of sCSF leaks' onset with obesity ( $80 \%$ of patients), elevated ICP ( $40 \%$ of patients), and obstructive sleep apnea (OSA) (43\% of patients). ${ }^{19,20}$ This association is important because it is known that ICP spike during apneic events that suggest episodic rises in ICP may also contribute to skull base erosion over time. ${ }^{21}$ After surgical repair of lateral skull base $\mathrm{SCSF}$ leaks, it appears safe to resume CPAP treatment of OSA. ${ }^{22}$ Spontaneous CSF leaks have the highest recurrence rate following surgical repair (25\%-87\%), compared with less than $10 \%$ for other etiologies. ${ }^{18,23}$ In a retrospective analysis of 72 patients over a 10 -year period, Mirza et $\mathrm{al}^{24}$ observed that 13 out of 29 patients with spontaneous CSF leaks (46\%) had evidence of elevated ICP, in which 6 of the 13 patients (46\%) had a recurrence. Chaaban et $\mathrm{al}^{25}$ on the basis of their 5-year prospective study on 46 patients with 56 spontaneous CSF leaks, concluded that the successful treatment of elevated ICP in combination with endoscopic leak repair can provide high success rates (93\% primary and $100 \%$ secondary).

\section{3 | OBJECTIVE OF THE REVIEW}

Cerebrospinal fistula might occur due to several etiologies, spontaneously, post-traumatic, post-surgery head neoplasm, 
inflammatory diseases eroding the skull base, or congenital malformations. Since 2000, advancements in endoscopic technology have led to the consolidation of the transnasal endoscopic approach repair.

The purpose of this review was to summarize the success rate for endoscopic CSF leak repair as well as whether specific techniques or materials do influence their primary success rate. In addition, the impact of epidemiology, etiology, clinical presentation, site and dimension of the fistula, and management of success-related factors, including the time to perform surgery and information on the effect of adjunctive measures such as lumbar drain and intrathecal fluorescein, were analyzed through a review of the latest advances in endoscopic CSF management published over the past 10 years of the published English literature.

\section{4 | MATERIALS AND METHODS}

A systematic review was performed using independently developed search strategies in the literature review methodology, and it was written in accordance with the PRISMA statement to guarantee a scientific strategy of research to limit bias by a systematic assembly, critical appraisal, and synthesis of all the most relevant studies published on this topic. ${ }^{26,27}$ The databases interrogated included PubMed Clinical Queries http://www.ncbi.nlm.nih.gov. Reference lists from the identified articles were searched and cross-referenced to identify additional relevant articles, and national experts in the field were contacted to identify unpublished data. The search terms included the following various combinations to maximize the yield: Anterior skull base defect AND Anterior cerebrospinal fluid leaks AND Endoscopic reconstruction AND Sinonasal malignancies AND Reconstructive technique AND Double

T A B L E 2 Quality assessment for case series

1 Case series collected in more than one center (i.e., multicenter study)

2 Is the hypothesis/aim/objective of the study clearly described?

3 Are the inclusion and exclusion criteria (case definition) clearly reported?

4 Is there a clear definition of the outcomes reported?

5 Were data collected prospectively?

6 Is there an explicit statement that patients were recruited consecutively?

7 Are the main findings of the study clearly described?

8 Are outcomes stratified (i.e., by disease stage, abnormal test results, patients characteristics)?
F I G URE 1 Statistical assessment was performed primarily with descriptive data [Color figure can be viewed at wileyonlinelibrary.com]

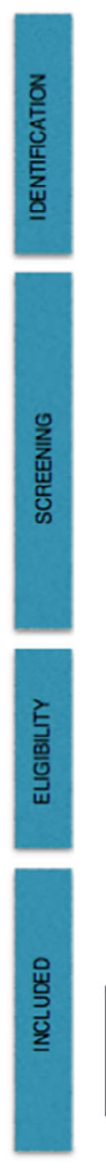

Citations excluded (633):

Titles not relevant (416)

Duplicate titles (52)

Published before 2007 (165)

References excluded (156):

Articles not in English (11)

Not human studies (67)

Case reports (27)

Letters and reviews (18)

Technical notes (33)

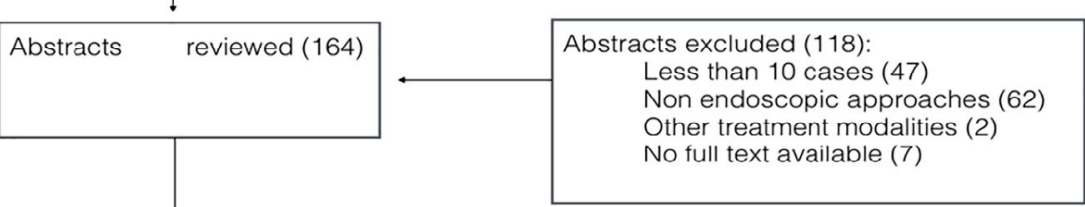

Excluded (18):

Not clearly describing aim/ objective

(6)

Statistical data not clearly shown or detachable (5)

Heterogenous sample (7)

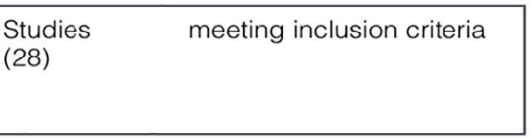


T A B L E 3 Selected studies

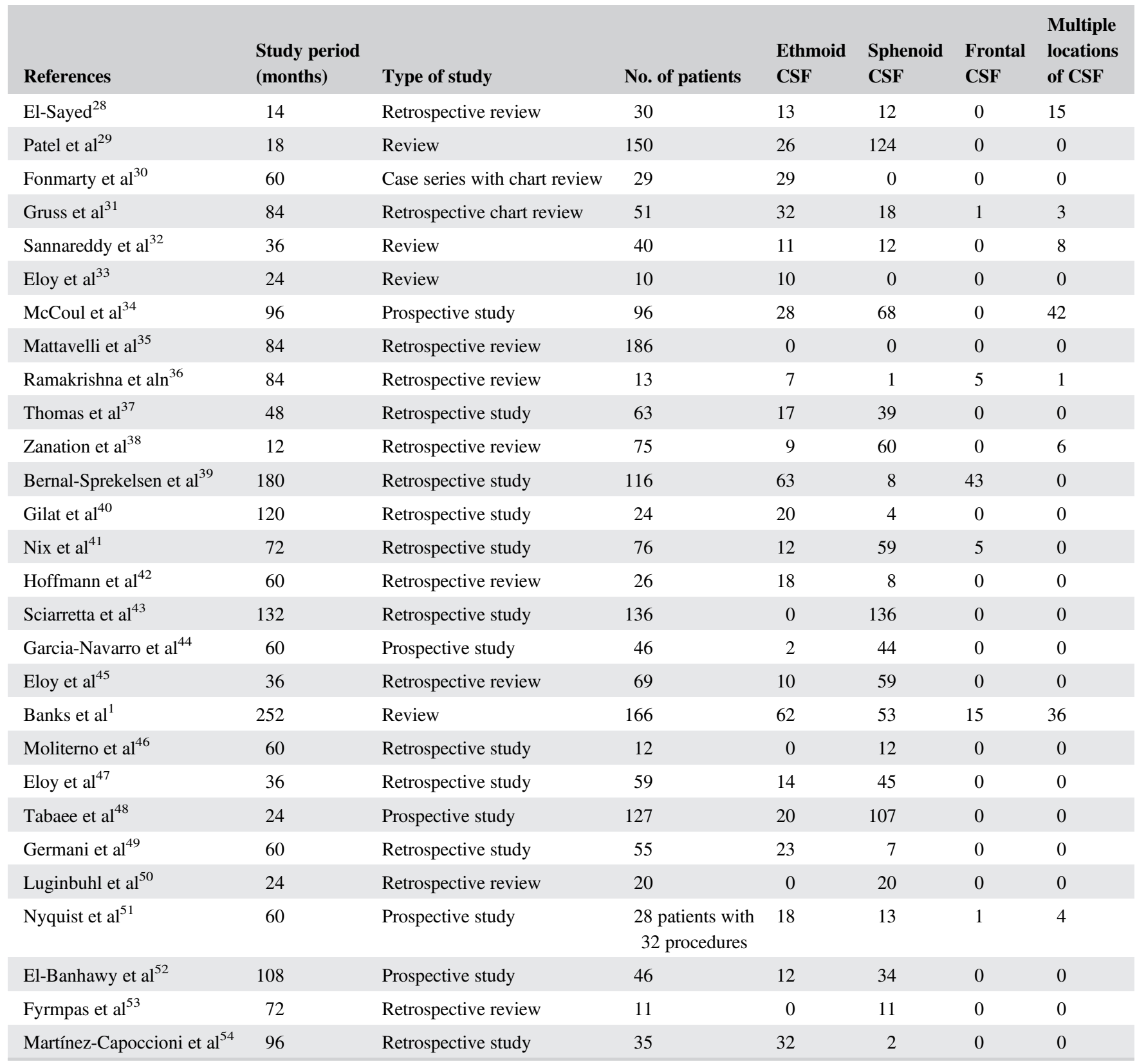

Abbreviation: CSF, cerebrospinal fluid.

flap technique AND Nasoseptal flap AND Inferior turbinate flap AND Medial turbinate flap AND Multilayer reconstruction AND Iliotibial graft AND Graft. The search was performed for the first time on December 2017 and was set to automatically update periodically until September 2018. First, duplicates were removed electronically. Then, abstracts were reviewed to exclude obviously irrelevant articles. Non-English language papers, experimental studies, and case reports were excluded. The inclusion criteria were set a priori and deliberately kept wide to encompass as many articles as possible without compromising the validity of the results, and they included articles (1) published from 2007 onwards;
(2) reporting published series of $>10$ patients who underwent endoscopic repair of CSF leaks; (3) about endoscopic transnasal CSF leaks' repair; (4) excluding open approaches; (5) reporting data distinguishing results of endoscopic procedures that are divided into multilayer or single layer; (6) considering different endoscopic techniques, such as naso septal flap (NSF), inferior turbinate flap (ITF), middle turbinate flap (MTF), fascia lata, and abdominal fat graft; (7) with a clear description of CSF leaks' location (ethmoid, sphenoid, frontal, and multiple sites); (8) dividing CSF leaks' etiologies: iatrogenic, neoplastic (benign tumors and malignant tumors), and spontaneous; and (9) excluding traumatic etiology. We filtered 
T A B LE 4 Repair technique and outcome

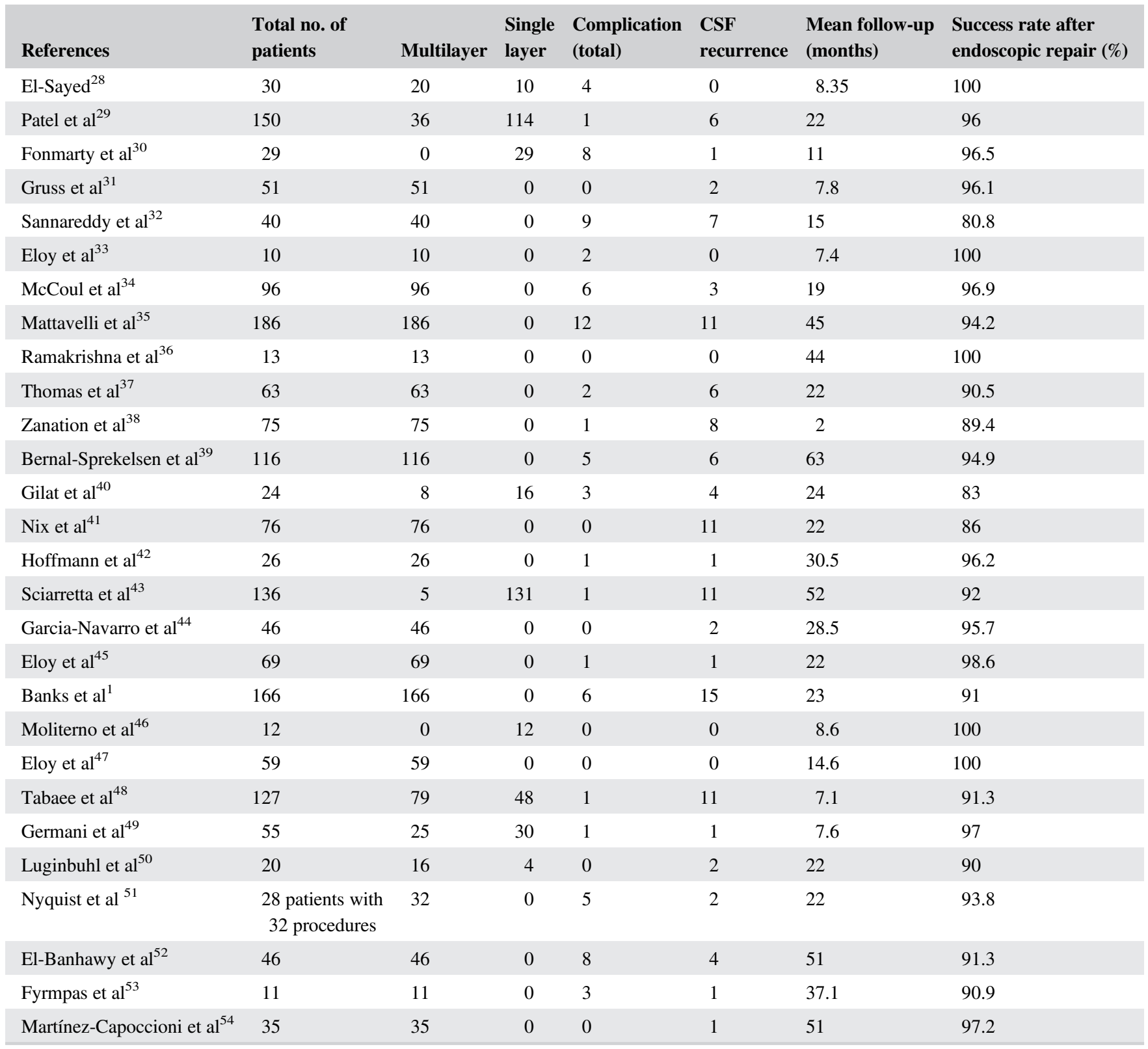

Abbreviation: CSF, cerebrospinal fluid.

the studies to ensure that only data from centers that had published on at least 10 patients were included in the review; this was done as a quality assurance measure as there are several case series in the literature, which have published the results of small numbers of cases spanning several years. We chose as success rate of endoscopic CSF leaks' repair at the first surgery as the primary measure of outcome. Abstracts were analyzed to identify papers that fulfilled the inclusion criteria, and a first qualitative and descriptive review-analysis of selected articles was carried on, whereas, exclusively, publications clearly describing their aim and objectives, their inclusion and exclusion criteria, with clear or detachable statistical data, reporting success rates, and well describing the surgical techniques and postoperative complications were included in our meta-analysis. All included papers were graded using the NICE scoring scale for retrospective case series (available at: http://www. nice.org.uk/nicemedia/pdf/Appendix_04_qualityofcase_series_ form_preop.pdf; Table 2).

Fisher's exact test was used for statistical analysis of categorical data for the descriptive review, and a value of $P<.05$ was considered significant. The pooled estimate of each statistic was calculated using the Freeman-Tukey double arcsine transformation to stabilize the variances. A random effect model was specified, using the method by DerSimonian and Laird, with the estimate of heterogeneity being taken from the inverse-variance fixed-effect model. Heterogeneity is also 


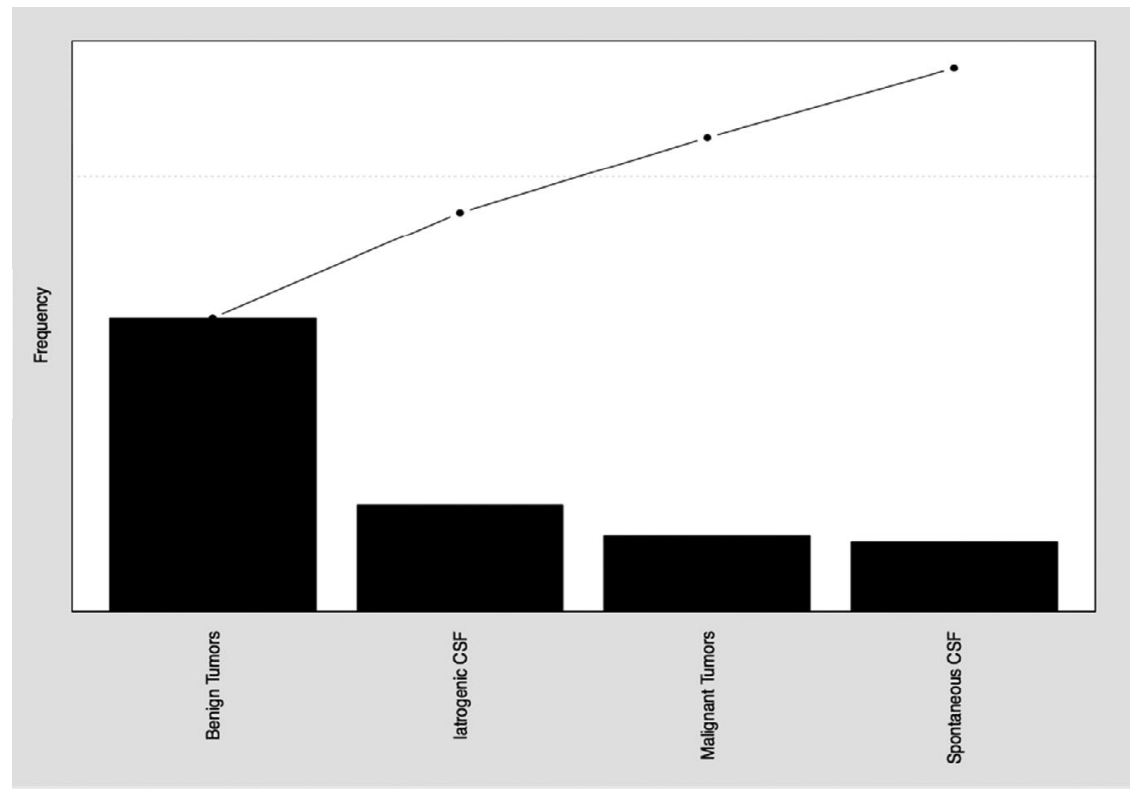

F I G URE 2 Because individual data were not available, we have looked at the macrolevel correlations between articles

TA B L E 5 Neoplastic and spontaneous CSF leaks compared by the dimension of CSF leaks

\begin{tabular}{llc} 
Etiology & Coefficient & $\boldsymbol{P}$ \\
\hline Neoplastic & -0.58 & $.25^{*}$ \\
\hline Iatrogenic & -0.19 & .88 \\
\hline Spontaneous & -0.98 & $.01 *$ \\
\hline
\end{tabular}

Abbreviation: CSF, cerebrospinal fluid.

*Statically significant.

quantified using the $I$-squared measure. All analyses were performed using STATA version 13 (StataCorp. 2013, Stata Statistical Software: Release 13, College Station, TX: StataCorp LP). The possibility of publication bias was evaluated with the Begg and Egger tests as well as visual inspection of the funnel plot. When possible, results are described in accordance with the PRISMA guidelines for reporting meta-analyses, with $95 \%$ confidence intervals reported throughout. When studies have low heterogeneity (pragmatically, $I^{2}<25 \%$ ), the differences between reported outcomes can be explained simply by the observed natural differences between patients. In this case, we can consider that all patients are part of the same larger pool. A fixed-effects meta-analysis is appropriate in which each patient is given approximately equal weight.

\section{5 | RESULTS}

The various stages of systematically assessing the abstracts and reasons for exclusion from the review are described in Figure 1. Selected studies were summarized in Table 3. As for their quality, as assessed by the quality assessment criteria outlined above, 4 papers scored eight or seven, 9 scored six, 5 scored five and 10 papers scored four or three. Of these,

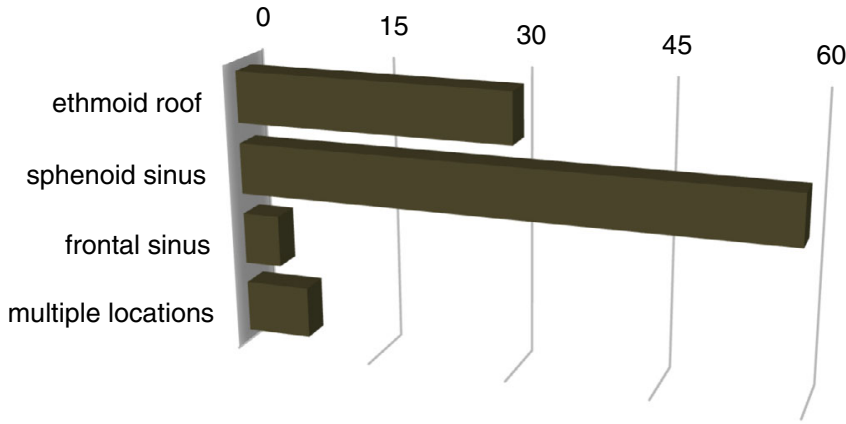

F I G U RE 3 Site of CSF leaks. CSF, cerebrospinal fluid [Color figure can be viewed at wileyonlinelibrary.com]

5 were prospective studies and 23 were retrospective studies or review. The study periods range from 12 to 252 months with a median of 72 months.

A total of 1767 patients were identified; among them, 52\% ( $\mathrm{n}=937)$ were male and $48 \%(\mathrm{n}=857)$ were female. The median age was 51 years (range, $15-86$ years). Factors related to CSF leaks' characteristics, concerning their size, etiology, location site, and factors related to adjuvant treatment and repair technique, together with the success rate and postoperative period description, gave the following outcomes (Table 4).

\section{1 | Factors relating to CSF leaks' characteristics}

- Size: The median defect size measured was $2.81 \mathrm{~cm}^{2}$. In $59 \%$ of the patients $(395 / 667)$, the defect size was $<2 \mathrm{~cm}$ in maximum dimension, whereas in the remaining $41 \%$ (272 patients), the size was $>2 \mathrm{~cm}$. 


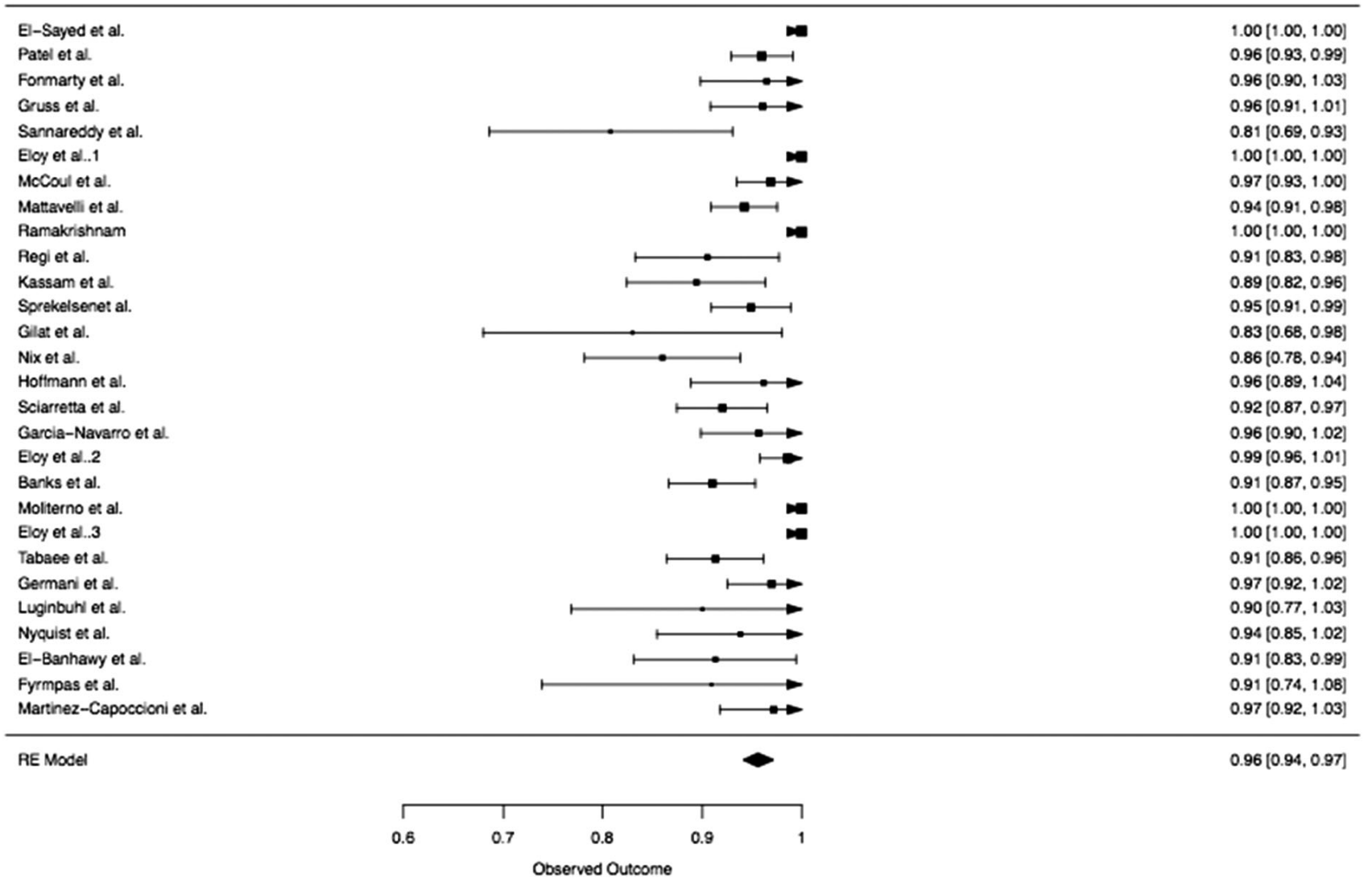

FIGURE 4 Forest plot of success rate

F I G URE 5 Funnel plot—success rate [Color figure can be viewed at wileyonlinelibrary.com]

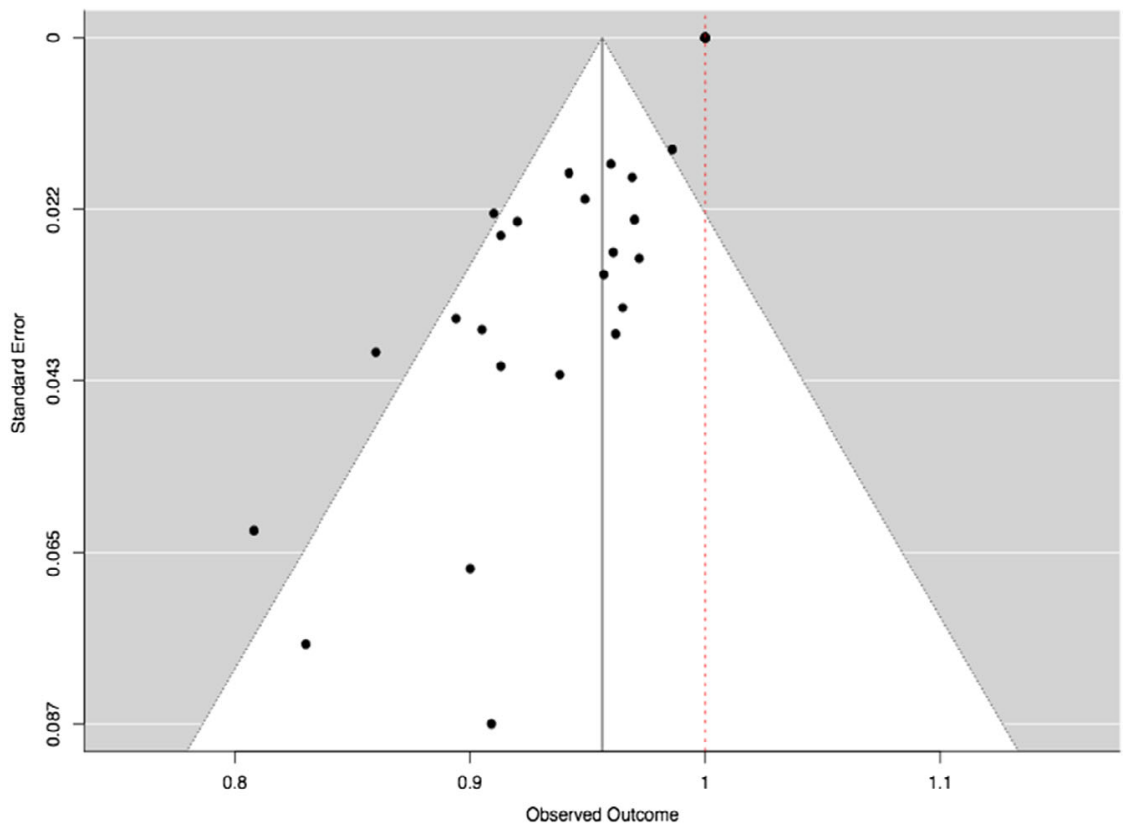

- Etiology: CSF leaks were divided into three categories: neoplastic $(67 \%)$, spontaneous $(14 \%)$, and iatrogenic (19\%) (Figure 2). Our data have shown that there was a relationship between CSF leaks' etiology and their size if it was greater than $2 \mathrm{~cm}$ in maximum diameter. Table 5 shows that there was a statistically significant difference in the group of neoplastic and spontaneous CSF leaks compared by the dimension of CSF leaks.

- Location site: In 488 (30\%) patients, the leak was located in the ethmoid roof, whereas in $956(59 \%)$ patients in the 
sphenoid sinus and in the remaining $70(4 \%)$ patients in the frontal sinus. Multiple locations were found in 115 cases (7\%) (Figure 3). Ethmoid location resulted to be a

T A B L E 6 Onset of CSF leak recurrence-Statistical analysis

\begin{tabular}{|lcc|}
\hline Variable & Coefficient & $\boldsymbol{P}$ \\
\hline Intercept & -0.09 & .45 \\
\hline Size $>2 \mathrm{~cm}$ & -0.05 & .52 \\
\hline Ethmoid location & 0.14 & .42 \\
\hline Sphenoid location & 0.10 & .44 \\
\hline Benign tumors & 0.04 & .22 \\
\hline Malignant tumors & 0.11 & .68 \\
\hline Prior radiation therapy & 0.00 & .91 \\
\hline
\end{tabular}

Abbreviation: CSF, cerebrospinal fluid.

T A B L E 7 Linear probability model with length of hospital stays longer than 7.5 days as a response variable

\begin{tabular}{|lcc|}
\hline Variable & Coefficient & $\boldsymbol{P}$ \\
\hline Intercept & 0.90 & $.01^{*}$ \\
\hline Ethmoid location & -1.06 & $.02^{*}$ \\
\hline Sphenoid location & -0.73 & $.04 *$ \\
\hline Benign tumors & -0.11 & .66 \\
\hline Malignant tumors & 0.68 & $.06^{*}$ \\
\hline Prior radiation therapy & -0.01 & .64 \\
\hline
\end{tabular}

*Statically significant. predictive factor for CSF leaks sized more than $2 \mathrm{~cm}$ in their maximum diameter $(P$ value $=.03)$.

\section{2 | Factors relating to adjuvant management}

- Intrathecal fluorescein: Fluorescein injection for detection of CSF leaks was used in 589 patients (33.3\%).

- Lumbar drain: 703 lumbar drains were used. The duration of the use varied from 1 to 8 days, in which most studies reported its use within the second or at least fifth day after surgery. The benefit of lumbar drain usage could not be calculated due to the limited data provided by the studies.

\section{3 | Factors relating to repair}

- Reconstruction technique: A multilayer reconstruction was fashioned in 1405 patients, and in other 394 patients, only a single-layer repair technique was used. In our series, the fascia lata was harvested in 1085 patients (61\%), NSF in 979 (55\%), and Janus flap (bilateral NSF) in 20 (1.1\%). MTF was harvested in 14 patients $(0.7 \%)$, and ITF in only 7 cases $(0.4 \%)$. Abdominal fat graft was performed in 836 patients (47\%), whereas high-viscosity polymethylmethacrylate, a variety of injectable cements, was used in 12 patients $(0.7 \%)$.

- Success rate: Pooling data from 1767 primary repairs reported a success rate of $96 \%$. CSF leak recurrences were found in $71(4 \%)$ patients. Median time of recurrence was 66 days (range 2-1095 days). A revision surgery was required in 55 cases $(3 \%)$.

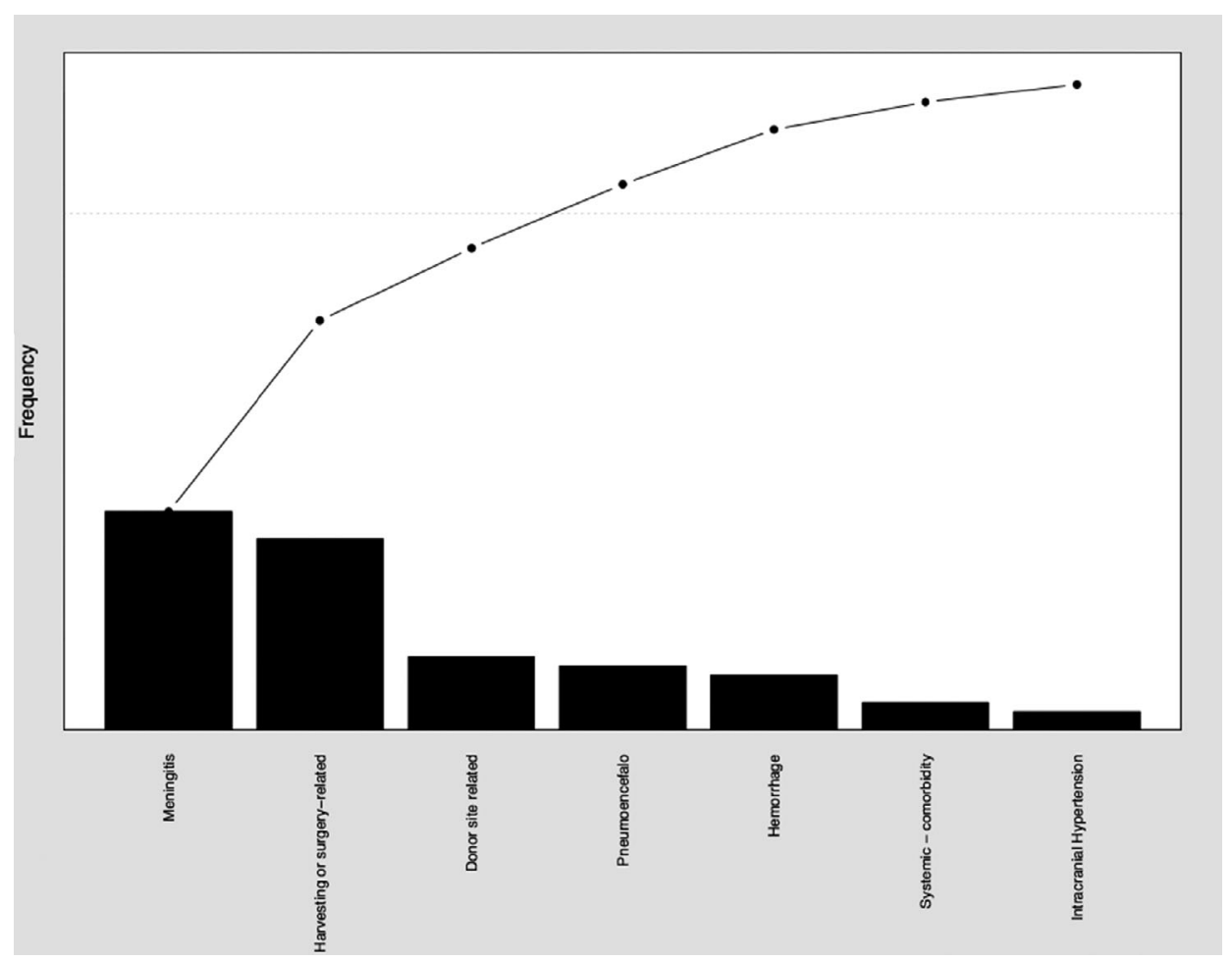

F I G U RE 6 Response variable: proportion of individuals who had major complications 
Heterogeneity of the results between the studies was assessed graphically by Forest plots and statistically using the quantity $I^{2}$ that describes the percentage of total variation across studies that is attributable to heterogeneity rather than chance (Figure 4). As shown below, high figures indicate greater homogeneity index in the data (Figure 5).

Both in the Forest plot and in the Funnel plot, SEs of the success rates were estimated through the classic estimator of the SE of a proportion. Significant predictive factors were not found regarding the onset of CSF leak recurrence (Table 6).

\section{4 | Factors related to postoperative period}

Postoperative nasal packing was used in 1207 patients (69\%). Median hospital stay was 8 days (range 5-11 days). We used a linear probability model taking the length of hospital stays longer than 7.5 days as a response variable. The results showed that "ethmoid location," "sphenoid location," and "malignant tumors" were predicting factors for the length of the hospital stay (Table 7). Complications (Figure 6) occurred in a total of 81 patients (4.5\%); out of these, 43 were categorized in major complications (meningitis, pneumocephalus, hemorrhage, intracranial hypertension) and 38 in minor complications (headaches, postoperative sinusitis, crusting, synechiae, hematoma, mucocele). The strongest predictors for complications were "malignant tumors" and "prior radiation

T A B LE 8 Related factors with major complications

\begin{tabular}{lcr} 
Variable & Coefficient & \multicolumn{1}{l}{$\boldsymbol{P}$} \\
\hline Intercept & 0.11 & .04 \\
\hline Size $>2 \mathrm{~cm}$ & 0.06 & .05 \\
\hline Ethmoid location & -0.14 & .06 \\
\hline Sphenoid location & 0.15 & .02 \\
\hline Benign tumors & 0.13 & $<.01$ \\
\hline Malignant tumors & -0.30 & .01 \\
\hline Prior radiation therapy & -0.01 & $<.01$ \\
\hline
\end{tabular}

T A B LE 9 Predictive factors regarding the onset of minor complications

\begin{tabular}{lcc} 
Variable & Coefficient & $\boldsymbol{P}$ \\
\hline Intercept & -0.09 & .45 \\
\hline Size $>2 \mathrm{~cm}$ & -0.05 & .52 \\
\hline Ethmoid location & 0.14 & .42 \\
\hline Sphenoid location & 0.10 & .44 \\
\hline Benign tumors & 0.04 & .22 \\
\hline Malignant tumors & 0.11 & .68 \\
\hline Prior radiation therapy & 0.00 & .91 \\
\hline
\end{tabular}

therapy" (Table 8). Conversely, significant predictive factors for the onset of minor complications have not been found (Table 9).

\section{6 | DISCUSSION}

Several authors have documented, in the literature, an overall success rate of surgical CSF leak repair ranging from $97 \%$ to $99 \%$, and they have demonstrate the efficacy of endoscopic repair through many reports. ${ }^{1}$ Psaltis et al, in a meta-analysis of 55 studies involving 1778 fistula repairs, observed a success rate of $90.6 \%$ following first endoscopic repair for CSF rhinorrhea. ${ }^{55}$ Kirtane and Upadhyayasr analyzed the largest series of endoscopic repair of CSF leaks and reported a primary success rate of $96.63 \%$ and $98.88 \%$ after revision surgery. ${ }^{56}$

The long-term success of endoscopic repair is influenced by CSF leak etiology. Several studies indicate an increased failure among SCSF leak repair, especially in patients with increased ICP. ${ }^{24}$ In a review of long-term outcomes of endoscopic repair, Zuckerman et $\mathrm{al}^{57}$ focused on the timing of recurrent CSF leaks. The average time for recurrence in their series was 7 months, ranging from 1 to 25 months. Banks et al observed spontaneous leaks recurring at 7 months (median range: 4 days-24 months) and traumatic leaks recurring at 4 months (median range: 4 days-29 months). ${ }^{1}$ Nasal crusting is the most common morbidity, and it occurs in more than $95 \%$ of patients (observed at 1 month postoperatively), but about $50 \%$ of them achieve crust-free nasal cavity objectivity by 3 months postoperatively. ${ }^{28}$ Addition sinonasal complications include nasal synechiae (9\%), alar sill burns (5\%), maxillary nerve hypoesthesia (2\%), palatal hypoesthesia (7\%), incisor hypoesthesia (11\%), serous otitis media (2\%), and taste disturbance $(7 \%)$ and malodor. Most of these complications are temporary, and most patients recover a full nasal function by 6 months after surgery. ${ }^{58}$ As previously mentioned, the resolution of these surgical sequelae requires intense postoperative care.

In our study, independent analysis of many factors (size, site, ICP, surgical technique, previous RT) was difficult, primarily because of the potential interdependence of different criteria, with certain locations of the skull base more characteristically associated with neoplastic, spontaneous, or iatrogenic etiology. Accordingly to our results, when we compared reconstruction outcomes by subsite of defect, there were no clear differences between vascularized vs. nonvascularized reconstruction techniques for any individual subsite. It appears that specific characteristics of the defect might be more relevant of selection of reconstructive techniques, rather than anatomic subsite. A retrospective study published by Gruss et al revealed that the dimension of the dural defect correlates with recurrences of CSF leak. ${ }^{31}$ Flap surgery is highly successful with small defects with a flap failure rate of $3.8 \%$ for defects 
less than $2.0 \mathrm{~cm} .{ }^{2}$ However, the $16.7 \%$ of defects of $2.0 \mathrm{~cm}^{2}$ in dimension or larger failed $(P=0.03)$. In a systematic review of the literature, Harvey et al concluded that for skull base defects larger than $3 \mathrm{~cm}$, reconstruction with a vascularized flap had a significant advantage over free grafting in preventing postoperative CSFL. ${ }^{59}$ On the other hand, small defects $(<10 \mathrm{~mm})$ generally do not need repair by vascular flaps. ${ }^{60}$ Data emerging from a study performed by TurriZanoni et $\mathrm{al}^{61}$ outlined that it is not the defect size that makes the reconstruction complex; much more important is whether the borders of the defects can be identified and exposed, since this determines the ease, complexity, or even impossibility of the procedure. The absence of these borders precludes the positioning of the inlay grafts, and it significantly increases the risk of postoperative leakage. Our data have shown that CSF leaks larger than $2 \mathrm{~cm}^{2}$ were more associated to neoplastic and spontaneous etiologies and successfully treated using vascularized flaps. An increasing popularity of the vascularized pedicled flaps compared with the use of free-tissue grafts has been found; the pedicled nasoseptal flap (PNSF) is currently the workhorse of endoscopic skull base repair, and it represents the principal advancement in endoscopic reconstruction by vascularized flap and represents the technique of choice for several authors. In an anatomical and radiological study, Pinheiro-Neto et al ${ }^{62}$ verified the sufficiency of the flap to cover the ASB defect after endoscopic craniofacial resection, concluding that the dimensions of the PNSF are theoretically sufficient to cover the ASB defect completely. Eloy et al in their retrospective analysis ${ }^{33}$ have studied the use of PNSF for revision repair of recurrent CSF rhinorrhea after failed transcranial approach and the success rate in this series was of $100 \%$. Our systematic review data showed an overall success rate of $96 \%$ after the first endoscopic attempt. These results remain superior to the previous systematic review published by Psaltis et $\mathrm{al}^{55}$ in 2012, probably because of considerable evolution in endoscopic surgery over the last few decades, in which advancements in endoscopic instrumentation, imagebased navigation systems, and refinements in surgical techniques have all contributed to reducing skull base reconstruction failures. Psaltis et $\mathrm{al}^{55}$ also pointed out the evidence that the endoscopic approach is not only efficacious but also safe. According to this, the overall complication rate in our study was very low (4.5\%), and major complications (meningitis, pneumocephalus, hemorrhage, intracranial hypertension) occurred in 43 out of a total of 1767 patients (2.4\%), and they were more associated with malignant tumors and prior radiation therapy. In terms of short-term nasal morbidity, De Almeida et $\mathrm{al}^{63}$ reported nasal crusting being the most common (98\%) symptom reported, followed by nasal discharge (46\%), whereas loss of smell was reported by only $9.5 \%$ of the patients. Sinonasal function did appear to improve over time for these patients, in contrast of loss of smell which turned to be often permanent. Contrariwise to major complications, significant predictive factors have not been found regarding the onset of minor complications in our meta-analysis, and the efficacy of fibrin glue in preventing CSF leaks remains controversial. Although histopathological studies suggest that fibrin glue may trigger an inflammatory response that may promote healing, several studies have reported a success rate of $97 \%$ with fibrin glue and $92 \%-100 \%$ without glue for CSF leak success repair rate. Several authors have reported successful results with relatively consistent use of lumbar drain, whereas others have reported similar results without lumbar drain placement. ${ }^{64}$ On the basis of a metaanalysis of 14 studies comprising 289 CSF fistulae repairs, Hassan et al advocated the use of lumbar drains for 3-5 days with idiopathic leaks, posttraumatic leaks, leaks associated with large defect $(>15 \mathrm{~mm})$, recurrent leaks, and leaks associated with a meningocele. ${ }^{12}$

\section{7 | CONCLUSION}

The principles of multilayer reconstructions and the routine use of vascularized flaps in expanded endonasal surgery have reduced postoperative CSF leaks' failure rates between $5 \%$ and $10 \%$ (4\% in this meta-analysis). Our data revealed that surgical outcomes have been gradually improved over the years, hand in hand with the advances in surgical skills and expertise, technological evolutions, and refinements in surgical technique, emphasizing the importance of experience in this field. This systematic review shares many of the limitations inherent to all meta-analyses that stem from multiple sources of bias. Available data and case-series have usually been heterogeneous, reporting different characteristics of defects and reconstruction techniques, thus precluding meaningful conclusions. It is consequently difficult to make evidence-based decisions to optimize reconstructive options for each specific type of skull base defect. It appears clear that effective endoscopic ASB closure may be achieved by multiple reconstructive techniques including overlay graft positioning, multilayer grafts, and vascularized flaps, which should be tailored case by case according to the patient and defect conditions.

Future perspective randomized trials with comparable cohorts should aim to improve our levels of evidence for treatment decision making and will help us to understand and manage patients at high risk for a postoperative CSF leak, especially those who have been previously irradiated and/or require revision surgery.

\section{ACKNOWLEDGMENT}

This paper was Alessandra Iavarone's thesis in Otorhinolaryngology in September 2018. 


\section{CONFLICT OF INTEREST}

The authors declare no potential conflict of interest.

\section{AUTHOR CONTRIBUTIONS}

This manuscript was approved by all authors, and each author has participated actively in designing and writing this article, and has contributed to the following: (a) conception and design or analysis and interpretation of data, (b) drafting of the manuscript or revising it for important intellectual content, and (c) final approval of the version to be published. Specifically, A.I. is the main writer of the work; G.M. is the main ideator of the study, she helped with reviewing the final proof of the manuscript and gave final approval for this version of the manuscript; P.L., M.S.L., F.M., and L.V.C. assisted in data collection and literature review; R.S. and G.P.S. helped with reviewing the final proof of the manuscript and provided assistance with final version approval; G.A. assisted with statistical analysis. Furthermore, this manuscript has not been published nor is it under consideration by other journals or editors.

\section{ORCID}

Paolo Luparello (D) https://orcid.org/0000-0002-1856-9372 Lara Valentina Comini @ https://orcid.org/0000-0002-36391504

Giuditta Mannelli (1D https://orcid.org/0000-0001-7079-3964

\section{REFERENCES}

1. Banks CA, Palmer JN, Chiu AG, et al. Endoscopic closure of CSF rhinorrhea: 193 cases over 21 years. Otolaringolog Head and Neck Surgery. 2009;140(6):826-833.

2. Dohlman G. Spontaneous cerebrospinal rhinorrhoea; case operated by rhinologic methods. Acta Otolaryngol Suppl. 1948;67:20-23.

3. Chandler JR. Iatrogenic cerebrospinal rhinorrhea. Its surgical repair. Trans Am Acad Ophthalmol Otolaryngol. 1970;74(3): 576-584.

4. Hirsh O. Successful closure of cerebrospinal fluid rhinorrhea by endonasal surgery. AMA Arch Otolaryngol. 1952;56(1):1-12.

5. Vrabec DP and Hallberg EO. Cerebrospinal fluid rhinorrhea. Intranasal approach, review of the literature, and report of a case. Arch Otolaryngol. 1964;80:218-229

6. Lehrer J, Deutsch H. Intranasal surgery for cerebrospinal fluid rhinorrhea. Mt Sinai J Med. 1970;37(2):133-138.

7. Wigand ME. Transversal ethmoidectomy under endoscopic control. Rhinology. 1981;19(1):7-15.

8. Mattox E, Kennedy DW. Endoscopic management of cerebrospinal fluid leaks and cephaloceles. Laryngoscope. 1990;100(8): 857-862.

9. Martin TJ, Loehrl TA. Endoscopic CSF leak repair. Curr Opin Otolaryngol Head Neck Surg. 2007;15(1):35-39.

10. Lopatin AS, Kapitanov DN. Endonasal endoscopic repair of spontaneous cerebrospinal fluid leaks. Arch Otolaryngol Head Neck Surg. 2003;129(8):859-863.
11. Gendeh BS, Mazita A, Selladurai BM, Jegan T, Jeevanan J, Misiran K. Endonasal endoscopic repair of anterior skull-base fistulas: the Kuala Lumpur experience. J Laryngol Otol. 2005;119 (11):866-874.

12. Hassan M, Hegazy CRL, Snyderman CH, Kassam A, Zweig J. Transnasal endoscopic repair of cerebrospinal fluid rhinorrhea: a meta-analysis. Laryngoscope. 2000;110(7):1166-1172.

13. Lindstom DR, Toohill RJ, Loehrl TA, Smith TL. Management of cerebrospinal fluid rhinorrhea: the medical college of Wisconsin experience. Laryngoscope. 2004;114(6):969-974.

14. Locatelli D, Rampa F, Acchiardi I, et al. Endoscopic endonasal approaches for repair of cerebrospinal fluid leaks: nine-year experience. Neurosurgery. 2006;58(4):246-256.

15. Sanderson JD, Kountakis SE, McMains KC. Endoscopic management of cerebrospinal fluid leaks. Facial Plast Surg. 2009;25(1): 29-37.

16. Schlosser RJ, Bolger WE. Management of multiple spontaneous nasal meningoencephaloceles. Laryngoscope. 2002;112(6): 980-985.

17. McMains KC, Gross CW, Kountakis SE. Endoscopic management of cerebrospinal fluid rhinorrhea. Laryngoscope. 2004;114(10): 1833-1837.

18. Schlosser RJ, Bolger WE. Nasal cerebrospinal fluid leaks: critical review and surgical considerations. Laryngoscope. 2004;114(2): 255-265.

19. Nelson RF, Roche JP, Gantz BJ, et al. Middle cranial fossa (mcf) approach without the use of lumbar drain for the management of spontaneous cerebral spinal fluid (CSF) leaks. Otol Neurotol. 2016;37(10):1625-1629.

20. Lobo BC, Baumanis MM, Nelson RF. Surgical repair of spontaneous cerebrospinal fluid (CSF) leaks: a systematic review. Laryngoscope Investig Otolaryngol. 2017;2(5):215-224.

21. Jennum P, Borgesen SE. Intracranial pressure and obstructive sleep apnea. Chest. 1989;95(2):279-283.

22. Wannemuehler TJ, Hubbell RD, Nelson RF. Tension pneumocephalus related to spontaneous skull base dehiscence in a patient on bipap. Otol Neurotol. 2016;37(9):e322-e324.

23. Woodworth BA, Prince A, Chiu AG. Spontaneous CSF leaks: a paradigm for definitive repair and management of intracranial hypertension. Otolaryngol Head Neck Surg. 2008;138(6):715-720.

24. Mirza S, Thaper A, McClelland L, Jones NS. Sinonasal cerebrospinal fluid leaks: management of 97 patients over 10 years. Laryngoscope. 2005;115(10):1774-1777.

25. Chaaban MR, Illing E, Railey KO, Woodworth BA. Spontaneous cerebrospinal fluid leak repair: a five year prospective evaluation. Laryngoscope. 2014;124:70-75.

26. Sedgwick P. Meta-analysis: testing for reporting bias. BMJ. 2015; 350:g7858.

27. Goodman S, Dickersin K. Metabias: a challenge for comparative effectiveness research. Ann Intern Med. 2011;155:61-62.

28. El-Sayed IH. Endoscopic reconstruction of skull base defects with the nasal septal flap. Skull Base. 2008;18(6):385-394.

29. Patel MR, Stadler ME, Snyderman CH, et al. How to choose? Endoscopic skull base reconstructive options and limitations. Skull Base. 2010;20(6):397-404.

30. Fonmarty D, Bastier PL, Lechot A, Gimbert E, de Gabory L. Assessment of abdominal fat graft to repair anterior skull base after malignant sinonasal tumor extirpation. Otolaryngol Head 
Neck Surg. 2016;154(3):540-546. https://doi.org/10.1177/ 0194599815620781 Epub 2015 Dec 8.

31. Gruss CL, Al Komser M, Aghi MK, et al. Risk factors for cerebrospinal leak after endoscopic skull base reconstruction with nasoseptal flap. Otolaryngol Head Neck Surg. 2014;151(3): 516-521.

32. Sannareddy RR, Rambabu K, Kumar V, Boola Gnana R, Ranjan A. Endoscopic management of CSF rhinorrhea. Neurol India. 2014;62(5):532-539.

33. Eloy JA, Patel SK, Shukla PA, Smith ML, Choudhry OJ, Liu JK. Triple-layer reconstruction technique for large cribriform defects after endoscopic endonasalresection of anterior skull base tumors. Int Forum Allergy Rhinol. 2013;3(3):204-211. https://doi.org/10. 1002/alr.21089 Epub 2012 Oct 4.

34. McCoul ED, Anand VK, Singh A, Nyquist GG, Schaberg MR, Schwartz TH. Long-term effectiveness of a reconstructive protocol using the nasoseptal flap after endoscopic skull base surgery. World Neurosurg. 2014;81(1):136-143. https://doi.org/10.1016/j. wneu.2012.08.011 Epub 2012 Sep 25.

35. Mattavelli D, Schreiber A, Ferrari M, et al. Three-layer reconstruction with iliotibial tract after endoscopic resection of sinonasal tumors: technical note. World Neurosurg. 2017;101:486-492.

36. Ramakrishnan VR, Terella AM, Poonia S, Chiu AG, Palmer JN. Osseous repair in minimally invasive reconstruction of anterior skull base defects. J Craniofac Surg. 2017;28(1):36-39. https://doi. org/10.1097/SCS.0000000000003170.

37. Thomas R, Chacko AG. Principles in skull base reconstruction following expanded endoscopic approaches. J Neurol Surg B Skull Base. 2016;77(4):358-363. https://doi.org/10.1055/s-00361579543 Epub 2016 Feb 26.

38. Zanation AM, Carrau RL, Snyderman CH, et al. Nasoseptal flap reconstruction of high flow intraoperative cerebral spinal fluid leaks during endoscopic skull base surgery. Am J Rhinol Allergy. 2009;23(5):518-521. https://doi.org/10.2500/ajra.2009.23.3378.

39. Bernal-Sprekelsen M, Rioja E, Enseñat J, et al. Management of anterior skull base defect depending on its size and location. Biomed Res Int. 2014;2014:34687350.

40. Gilat H, Rappaport Z, Yaniv E. Endoscopic transnasal cerebrospinal fluid leak repair: a 10 year experience. Isr Med Assoc J. 2011; 13(10):597-600.

41. Nix P, Tyagi A, Phillips N. Retrospective analysis of anterior skull base CSF leaks and endoscopic repairs at Leeds. $\mathrm{Br}$ J Neurosurg. 2016;30(4):422-426. https://doi.org/10.3109/02688697.2016. 1161176 Epub 2016 Mar 23

42. Hoffmann TK, El Hindy N, Müller OM, et al. Vascularised local and free flaps in anterior skull base reconstruction. Eur Arch Otorhinolaryngol. 2013;270(3):899-907. https://doi.org/10.1007/ s00405-012-2109-1 Epub 2012 Aug 10.

43. Sciarretta V, Mazzatenta D, Ciarpaglini R, Pasquini E, Farneti G, Frank G. Surgical repair of persisting CSF leaks following standard or extended endoscopic transsphenoidal surgery for pituitary tumor. Minim Invasive Neurosurg. 2010;53(2):55-59. https://doi. org/10.1055/s-0029-1246161 Epub 2010 Jun 8.

44. Garcia-Navarro V, Anand VK, Schwartz TH. Gasket seal closure for extended endonasal endoscopic skull base surgery: efficacy in a large case series. World Neurosurg. 2013;80(5):563-568.

45. Eloy JA, Choudhry OJ, Shukla PA, Kuperan AB, Friedel ME, Liu JK. Nasoseptal flap repair after endoscopic transsellar versus expanded endonasal approaches: is there an increased risk of postoperative cerebrospinal fluid leak? Laryngoscope. 2012;122 (6):1219-1225. https://doi.org/10.1002/lary.23285 Epub 2012 Apr 20.

46. Moliterno JA, Mubita LL, Huang C, Boockvar JA. High-viscosity polymethylmethacrylate cement for endoscopic anterior cranial basereconstruction. J Neurosurg. 2010;113(5):1100-1105. https:// doi.org/10.3171/2010.3.JNS09453 Epub 2010 Mar 26.

47. Eloy JA, Kuperan AB, Choudhry OJ, Harirchian S, Liu JK. Efficacy of the pedicled nasoseptal flap without cerebrospinal fluid (CSF) diversion for repair of skull base defects: incidence of postoperative CSF leaks. Int Forum Allergy Rhinol. 2012;2(5):397401. https://doi.org/10.1002/alr.21040 Epub 2012 Apr 23.

48. Tabaee A, Kassenoff TL, Kacker A, Anand VK. The efficacy of computer assisted surgery in the endoscopic management of cerebrospinal fluid rhinorrhea. Otolaryngol Head Neck Surg. 2005;133 (6):936-943.

49. Germani RM, Vivero R, Herzallah IR, Casiano RR. Endoscopic reconstruction of large anterior skull base defects using a cellular dermal allograft. Am J Rhinol. 2007;21(5):615-618.

50. Luginbuhl AJ, Campbell PG, Evans J, Rosen M. Endoscopic repair of high-flow cranial base defects using a bilayer button. Laryngoscope. 2010;120(5):876-880. https://doi.org/10.1002/lary. 20861.

51. Nyquist GG, Anand VK, Mehra S, Kacker A, Schwartz TH. Endoscopic endonasal repair of anterior skull base non-traumatic cerebrospinal fluid leaks, meningoceles, and encephaloceles. $J$ Neurosurg. 2010;113(5):961-966.

52. El-Banhawy OA, Halaka AN, Altuwaijri MA, Ayad H, ElSharnoby MM. Long-term outcome of endonasal endoscopic skull base reconstruction with nasal turbinate graft. Skull Base. 2008;18 (5):297-308. https://doi.org/10.1055/s-0028-1086055.

53. Fyrmpas G, Konstantinidis I, Selviaridis P, Constantinidis J. Management of spontaneous cerebrospinal fluid leaks of the sphenoid sinus: our experience. J Laryngol Otol. 2014;128(9):797-802. https://doi.org/10.1017/S0022215114001698 Epub 2014 Sep 2.

54. Martínez-Capoccioni G, Serramito-García R, Martín-Bailón M, García-Allut A, Martín-Martín C. Spontaneous cerebrospinal fluid leaks in the anterior skull base secondary to idiopathic intracranial hypertension. Eur Arch Otorhinolaryngol. 2017;274(5):21752181. https://doi.org/10.1007/s00405-017-4455-5 Epub 2017 Feb 7.

55. Psaltis AJ, Schlosser RJ, Banks CA, Yawn J, Soler ZM. A systematic review of the endoscopic repair of cerebrospinal fluid leaks. Otolaryngol Head Neck Surg. 2012;147(2):196-203.

56. Kirtane MV, Upadhyayasr G. Endoscopic CSF rhinorrhoea closure: our experience in 267 cases. Otolaryngol Head Neck Surg. 2005;132(2):208-212.

57. Zuckerman J, Stankiewicz JA, Chow JM. Long-term outcomes of endoscopic repair of cerebrospinal fluid leaks and meningoencephaloceles. Am J Rhinol. 2005;19(6):582-587.

58. Zanation AM, Snyderman CH, Carrau RL, Kassam AB, Gardner PA, Prevedello DM. Minimally invasive endoscopic pericranial flap: a new method for endonasal skull base reconstruction. Laryngoscope. 2009;119(1):13-18.

59. Harvey RJ, Parmar P, Sacks R, Zanation AM. Endoscopic skull base reconstruction of large dural defects: a systematic review of published evidence. Laryngoscope. 2012;122(2):452-459.

60. Harvey RJ, Nogueira FJ, Schlosser RJ, Patel SJ, Vellutini E, Stamm AC. Closure of large skull base defects after endoscopic 
transnasal craniotomy. Clinical article. J Neurosurg. 2009;111(2): 371-379.

61. Turri-Zanoni M, Zocchi J, Lambertoni A, et al. Endoscopic endonasal reconstruction of anterior skull base defects: what factors really affect the outcomes? World Neurosurg. 2018;116:e436e443.

62. Pinheiro-Neto CD, Ramos HF, Peris-Celda M, et al. Study of the nasoseptal flap for endoscopic anterior cranial base reconstruction. Laryngoscope. 2011;121(12):2514-2520.

63. De Almeida RJ, Snyderman CH, Gardner PA, Carrau RL, Vescan AD. Nasal morbidity following endoscopic skull base surgery: a prospective cohort study. Head Neck. 2011;33(4):547-551.
64. Casiano RR, Jassir D. Endoscopic cerebrospinal fluid rhinorrhea repair: is a lumbar drain necessary? Otolaryngol Head Neck Surg. 1999;121(6):745-750.

How to cite this article: Iavarone A, Luparello P, Lazio MS, et al. The surgical treatment of cerebrospinal fistula: Qualitative and quantitative analysis of indications and results. Head \& Neck. 2019;1-13. https://doi.org/10.1002/hed.25981 